DIVISION OF THE HUMANITIES AND SOCIAL SCIENCES

CALIFORNIA INSTITUTE OF TECHNOLOGY

PASADENA, CALIFORNIA 91125

THE SIMULTANEOUS ASCENDING AUCTION: DYNAMICS OF PRICE ADJUSTMENT IN EXPERIMENTS AND IN THE U.K. 3G SPECTRUM AUCTION

Charles R. Plott

Timothy C. Salmon

Florida State University

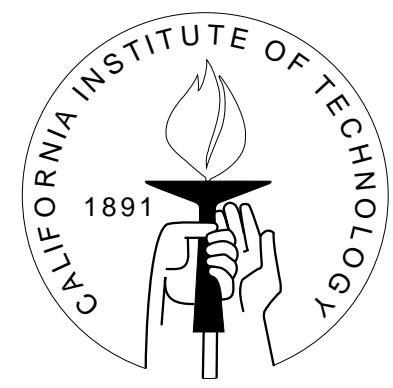

SOCIAL SCIENCE WORKING PAPER 1155 


\title{
The Simultaneous, Ascending Auction: Dynamics of Price Adjustment in Experiments and in the U.K. 3G Spectrum Auction
}

\author{
Charles R. Plott \\ The California institute of Technology
}

\author{
Timothy C. Salmon \\ Florida State University
}

July 18, 2002

\begin{abstract}
In this paper we develop a model of the behavior of bidders in simultaneous ascending auctions based on two principles: principle of surplus maximization and the principle of bid minimization. These principles lead to models of both price dynamics and equilibration, leading to disequilibrium structural equations that can be used for estimating bidder values. The intention behind the development of this methodology is to provide an auctioneer a method of extracting information during an auction about possible closing prices. We first benchmark the performance of the model with data from experimental auctions and then apply it to the U.K. UMTS or Third Generation Mobile auction.
\end{abstract}

Key Words: Multiple Unit Auctions, Value Estimation, Spectrum Auctions JEL Codes: C7, C9, C5

\section{Introduction}

In recent years attention has been focused on a particular form of auction generally called a simultaneous ascending auction (SAA), or simultaneous multiple round auction. It is the form of auction used by the Federal Communications Commission (FCC) for auctioning licenses to provide services in the electromagnetic broadcast spectrum and it has subsequently been adopted by other countries for the same purpose. Because of its widespread use and the fact that these auctions can continue for months with hundreds of rounds, interest exists in trying to model the dynamics of this price discovery process, including how long the auction will last and where the final prices might settle. This paper focuses on those issues.

A simultaneous ascending auction (SAA) is a multiple unit auction in which all of the objects are up for sale simultaneously using an English auction-like format in which the

prices of the objects are increased by the bidders until a stopping criteria is reached. In 
the US, auctions of this sort have yielded total net high bids of over $\$ 40$ billion $^{1}$ and recent auctions in the UK and Germany have raised $\$ 33$ billion $^{2}$ and $\$ 45$ billion $^{3}$ in single auctions. In the early auctions run by the FCC, some of them ran up to 6 months $^{4}$, although most of the more recent auctions have concluded within one. The third generation mobile auction in the UK lasted for 150 rounds or about a month and a half. Due to the length of time and amount of money involved in these auctions, it can be useful to both the auctioneer and bidders to be able to gain some insight into possible auction duration and revenue predictions as the auctions progress.

In this paper, we will develop a model of bidder behavior that is quite simple yet also quite powerful that is based on the ability of bidders to arbitrage between different types of items as the prices adjust during the auction and use it to derive an econometric technique for estimating bidder values. This model will first be tested on experimental data to assess the degree of accuracy of the fundamental behavioral principles that are at the core of the model and we also benchmark the performance of the estimation methodology on the experimental data. Finally, we will apply the estimation technique to the data generated by the recent U.K. Third Generation Mobile Auction (UK 3G).

The point of exploring this model is to determine if it is possible to extract some information from the pattern of bids in an auction while it is progressing that an auctioneer can use in determining the pacing of the auction. This is an important issue in practical auction conduct as each day an auction continues can cost bidders substantial sums of money in terms of cash outlays as well as opportunity costs. Proper conduct of an auction should seek to minimize this expense to the bidders. In conducting an auction of this sort an auctioneer has a number of tools at their disposal to impact pacing of the auction including setting minimum bid increments, round schedules and, in FCC auctions, determining stage transitions. The most important information the auctioneer needs in making decisions on how to adjust these elements is how far the auction is from concluding. If the current prices are in the hundred dollar range while the final prices are expected to be in the billion dollar range, there is little reason not to set very high minimum bid increments. As the auction nears conclusion, however, one might reasonably want to set lower bid increments in order to maximize efficiency and revenue. In our field application we will be trying to determine the extent to which this model would have been useful in providing such information to supplement any pre-auction estimates the auctioneer might have had.

Section 2 includes a brief overview of related literature and explains how and why

\footnotetext{
${ }^{1}$ This includes 33 total auctions as of April 2001. It should be noted that the total revenue raised by these auctions is much less than this total due to a large number of defaults following the first C Block PCS Auction, or FCC Auction \#5.

${ }^{2}$ This revenue total is for the UK Third Generation Wireless Acution (UK 3G). See Department of Trade and Industry Press Release P/2000/296 or for more information http://www.spectrumauctions.gov.uk/.

${ }^{3}$ This revenue total is for the Germany's Third Generation Wireless Acution. See http://www.regtp.de/ for more information.

${ }^{4}$ The two longest were the PCS C Block (Auction \#5) which began on 12/18/1995, ended 5/6/1996 and the PCS DEF Block (Auction \#11) which began 8/26/1996 and ended 1/14/1997.
} 
the model employed here departs from that literature. Section 3 describes the general rules of this class of auctions and the specializations used here. Section 4 will explain the theoretical structure behind the behavioral model and econometric analysis used in this paper. Section 5 will detail the experiments used to evaluate the model as well as the results of the experimental tests. Section 6 contains the results from an application of the model on the field data and section 7 will conclude.

\section{Background Literature}

The information extraction that is attempted in this paper takes the form of estimating bidder values in the auction using the data that is currently available in the auction. There is a well-developed existing literature on estimating bidder values in single unit auctions as in ?), ?), ?), and ?). The basic approach underlying all of these approaches is to assume that the bidders are bidding according to a risk-neutral Nash equilibrium bid function and then try to find distributions of values that are most consistent with the observed bids and the RNN assumption. The problem with this approach is that, as has been observed in countless laboratory experiments, bidders consistently bid well above the level predicted by a RNN equilibrium ${ }^{5}$.

To our knowledge there is only one other paper that tries to estimate bidder values in simultaneous ascending auctions with heterogeneous objects, ?). In this paper, the authors derive an estimator by solving for equilibrium bid functions under the assumptions of a common value single unit ascending auction and then try to apply it to specific licenses in one of the early FCC PCS auctions. This approach is highly problematic in regard to the fact that the estimator is misspecified for the environment to which it is applied. To their credit, the authors do note this difficulty. Even if one were to overlook that issue, though, it would not be possible to apply their methodology before the end of an auction. Their approach is based on the standard common value ascending auction bidding strategy based on bidders observing drop-out points of other bidders and then updating their beliefs accordingly on the value of the license. The problem is that until the auction is over, no bidder has necessarily dropped out of the bidding on that item, unless they have dropped out of the auction completely.

It is clear that the methodology applied in ?), while perhaps well developed for singleunit ascending auctions, is not well specified for SAAs. It is, however, useful as a benchmark for explaining how and why our approach is different from other approaches to estimating bidder values in auctions in the cited literature. All of the methodologies cited above rely on the assumption that bidders bid according to risk neutral Nash equilibrium bid functions. We believe that this is an overly restrictive assumption for the case of SAAs. While we could generate specific value structures with corresponding belief structures that would support

\footnotetext{
${ }^{5}$ The literature on this is large and while the contributors are quite contentiously divided as to why bidders bid above the RNNE level, the literature seems quite unanimous that it occurs systematically. See ?) for a good survey and introduction.
} 
the strategy we will be using as a Bayes Nash equilibrium, it will only satisfy any perfection criteria under very specific value distributions and even then only under hairline conditions on the preferences of the bidders. Thus trying to claim that its status as an equilibrium somehow lends it extra credibility seems less than compelling. Solving for more "realistic" equilibria is by no means an easy task and since there are likely to be a large number of them, we do not see a great deal to be gained in picking one out which is unlikely to be any more descriptive of the bidding behavior than the strategy we will be using. An examination of equilibrium behavior in ascending auctions that explains the theoretical results behind these statements more precisely can be found in ?).

Our approach is based on proposing a simple behavioral heuristic that can be taken as a simplification of the behavior of the bidders. Due to the difficulty of solving for equilibria in such environments and the tendency for bidders not to follow them precisely even in single unit auctions, there should be little loss from dropping the assumption that bidders would all solve for the same equilibrium and actually follow the equilibrium strategy carefully. Through the use of experiments we will show that it is a reasonable, though imperfect, approximation of actual bidding behavior. More importantly, we will show how this model can be used in estimating values from field auctions and will provide evidence from both the experimental and field data that although the model will fail on certain types of bidders, the ones for whom it will tend to succeed are the ones for which it is most important to succeed.

There is a related paper, ?), in which the authors find evidence that the behavioral model we develop in this paper does not fully capture the behavior in the U.K. auction and find that some bidders deviate substantially from it. We will make no claims in this paper that such deviations do not exist or that the proposed model should be expected to capture all of the behavioral elements that will exist in a real auction. Our goal is to take this simple model and determine how well it can perform in allowing us to form mid-auction predictions about closing prices in spite of its defects. To be very clear, we do not purport to show that this model can perfectly predict all of the individual bidding behavior observed in the auction nor is there any requirement that it be able to for the use to which we will apply it. It is actually not even necessarily true that perfectly predicting individual bids improves the performance of the model for our task as will be shown later. The question at hand is whether or not there is useful information contained in the pattern of bids of an ascending auction that can be extracted with this methodology that an auctioneer might be able to make use of. This is an empirical question that is not answered by looking only at the ability of the model to predict individual bids. There is certainly room for the construction of improvements to the model and accounting for some of the deviations found in ?) could help but currently there does not appear to be a systematic way to accomplish this. 


\section{Rules of Simultaneous Ascending Auctions}

There is not a single set form for a SAA, but rather there are a few basic rules with each auctioneer usually inserting their own variations to tailor the form to their needs. We will describe here the basic rules for this class of auctions as well as the specializations of these rules used for the experiments and the field application. There are six basic rules or classes of rules in these auctions.

1. Objects Auctioned Simultaneously: This means that the market for each item in the auction is simultaneously opened and closed. No item is considered sold or no market is considered closed until all items have been sold or all markets closed.

2. Structure of Bid Submission: The option here is a discrete versus continuous time process. In a continuous time process, bids may be submitted at any instant of time, with each submission generating a new set of provisional winners that are immediately announced. If a discrete process is used, the auction progresses in a series of sealed bid rounds. All bids are submitted in a sealed bid fashion during some designated period and then all bids and new provisional winners are announced simultaneously with a new sealed bid round beginning later. The experiments for this study were run using a continuous time process while the UK3G auction was conducted as a discrete time process.

3. Increment Requirements: As a mechanism for pacing an auction, an auctioneer will typically employ some requirement that a new bid meet a minimum increment requirement. In the experiments, there was a requirement that a new bid be $5 \%$ greater than the previous high bid on the item. In the UK3G auction, the auction began with a $5 \%$ increment and then that was adjusted down in steps as the auction progressed to a $1.5 \%$ increment.

4. Eligibility Rules. In some SAA's there are restrictions on how many and/or which items a bidder may place bids on in any given round. In the experiments, bidders were allowed to have a high bid on at most one item at a time ${ }^{6}$. In the UK3G auction, there was a similar restriction along with a restriction that certain bidders could not win one of the items. This will be discussed in more detail later.

5. Activity Rules: These rules are designed to spur activity in an auction and diminish a bidders incentive to wait until the end to bid. In the continuous time auctions studied here, there are no activity rules and the job of forcing bids is relegated to the stopping rule. For the UK3G auction, in any given round a bidder must either be a provisional winner from the previous round or must place a new bid. If they do not, the bidder

\footnotetext{
${ }^{6}$ The software does, however, allow for a bidder to raise their own high bid. As will be seen later, this allowed one bidder to make some very serious and costly mistakes. As followers of FCC auctions might be aware, such behavior, though potentially highly irrational, is not isolated to laboratory subjects.
} 
loses the right to bid in all future rounds. Many SAAs including the UK3G auction do allow bidders a certain number of waivers that can be used to suspend the activity rules in a given period for that bidder.

6. Stopping Rule: A stopping rule is used to determine when the auction closes. In a continuous time process, a countdown clock is typically used that starts the auction with a certain amount of time, three minutes in the experiments, and begins to count down. With each new bid, the clock is reset and the auction closes when the clock reaches zero. In a discrete time process, such as the UK3G auction, the auction ends the first period for which no new bids are submitted.

\section{Theory}

\subsection{Model of Bidder Behavior}

The model of bidder behavior that we will use in this paper is based on the following two principles:

Principle of Surplus Maximization: When faced with a decision, a bidder will place their bid on the item that maximizes their surplus given the current prices in the auction.

This implies a decision rule defined by equation 1 where $c_{i}(t)$ indicates the item that bidder $i$ places a bid on in period $t$. $v_{i}(k)$ denotes the value bidder $i$ places on item $k$ while $p_{t}(k)$ is the price of item $k$ at time $t$.

$$
c_{i}(t)=\arg \max _{k}\left[v_{i}(k)-p_{t}(k)\right]
$$

Principle of Minimum Bid: When choosing an amount to bid, the individual chooses the minimal possible price allowed by the system.

If we let $M$ be the minimum increment required for a new bid (e.g. .05), this principle says that the bid actually placed by an individual will be an amount equal to the minimum required bid which is defined as:

$$
p_{t}\left(c_{i}(t)\right)=(1+M) p_{t-1}\left(c_{i}(t)\right)
$$

The combination of the two principles suggest that the manner in which an individual bidder will behave is that they will examine the current price vector and compare it with their value function to determine which item would maximize their surplus. This is the item they will place a bid on. When placing the bid, they will bid at the minimum level required

by the auctioneer. This rule is a simple extrapolation of the basic single unit ascending auction strategy to multiple units and similar principles have been used successfully for modeling the behavior observed in combinatorial auctions as in ?) and was described in ?) as "straight-forward" bidding while being used to prove various properties of SAAs in the event that bidders behave in this manner. 


\subsection{Preferences}

In order to make inferences about the values held by bidders using this methodology, it is necessary to make some fairly strong conjectures about the underlying structure of bidder preferences. For other field applications, such conjectures would be based upon the information available to field observers as was done here. We will use the value function found in equation 3 to describe the structure of bidder preferences in this context. This is a simple value function that is specified to deal with auctions in which the difference in value between the items can be characterized by a single characteristic across which the items are vertically differentiated. For the field application used here, the important characteristic that differentiates objects is assumed to be the amount of $\mathrm{MHz}$ of spectrum in the license.

$$
v_{i}(k)=\gamma_{i} m(K)+\beta_{i}(m(k)-m(K))
$$

In equation $3, m(k)$ is the amount of the crucial characteristic, or $\mathrm{MHz}$ of spectrum, item $k$ contains and $m(K)$ is the number of $\mathrm{MHz}$ in the item with the smallest amount. The parameter $\gamma_{i}$ represents the dollar per $\mathrm{MHz}$ value for the first $m(K) \mathrm{MHz}$ in a license and $\beta_{i}$ reflects the value for marginal amounts of the characteristic above this base level. For simplicity, in the experimental setup we will set $\beta_{i}=\gamma_{i}$. When the model is fitted on the field data set, this will not be assumed.

\subsection{Econometric Specification}

The mechanism through which this model is able to identify the values a bidder has for the items is in the "switching" behavior evidenced by the bidder. In other words, if a bidder is bidding according to this model, they reveal the value differential they see between the items when they switch from bidding on one item to another. This switch reveals that for certain price combinations, bidding on item $A$ was more profitable but for the current prices, item $B$ is more profitable. Consider the hypothetical profile in table 1 . In this case, the first time the bidder places a bid, the price for item $A$ is 100 and item $B$ is 90 . According to the bidding rule, if item $A$ is worth at least 10 more than $B$, then the bidder should bid on $A$. In this case they did. The bidder continues to bid on $A$ until $p_{t}(A)=130$ and $p_{t}(B)=110$. In this case, the price differential is 20 and the bidder chooses instead to bid on $B$. If they were bidding according to this model, then they have just revealed that they believe $A$ is worth somewhere between 15 and 20 more than a $B$ item. The value estimation procedure effectively tracks any such switches made by a bidder and attempts to hone in on the most likely critical value of the price differential.

When presented with a choice situation of this sort, it is common to observe that bidders tend to make "errors" more often when the difference in surplus between the various items is small rather than when the difference is large. Consequently, we will be using a probabilistic version of the choice rule defined in equation $4 . \rho_{i}(k)$ is the probability that bidder $i$ will bid on item $k, p_{t}(k)$ is the price of item $k$ in period $t$. It should be clear that as the surplus for item $k$ grows relative to the surplus for the other items, this probability rises. The 


\begin{tabular}{ccccc}
\hline \hline Round & Item Bid on & $\mathbf{p}_{t}(\mathbf{A})$ & $\mathbf{p}_{t}(\mathbf{B})$ & $\mathbf{p}_{t}(\mathbf{A})-\mathbf{p}_{t}(\mathbf{B})$ \\
\hline \hline 5 & $\mathrm{~A}$ & 100 & 90 & 10 \\
\hline 8 & $\mathrm{~A}$ & 120 & 105 & 15 \\
\hline 12 & $\mathrm{~B}$ & 130 & 110 & 20 \\
\hline 15 & $\mathrm{~A}$ & 135 & 120 & 15 \\
\hline
\end{tabular}

Table 1: Hypothetical bid profile. If a bidder placed bids in this manner, they have revealed that they believe that an A item is worth somewhere between 15 and 20 more than a $\mathrm{B}$ item.

parameter $\lambda_{i}$ in this equation is a parameter that measures the propensity of the bidder to best respond.

$$
\rho_{i}(k)=\frac{\left(v_{i}(k)-p_{t}(k)\right)^{\lambda_{i}}}{\sum_{j}\left(v_{i}(j)-p_{t}(j)\right)^{\lambda_{i}}}
$$

Note that the methodology as described appears to be best at identifying differences in relative values of items in the auction. Specifically this implies a strong identification for $\beta$ as this is the parameter that measures the difference in value between the license groups. The actual level of the values, determined by $\gamma$, is more difficult to obtain identification for. When $\beta=\gamma$, the identification is trivial but otherwise this requires a careful specification of the probabilistic choice function. Common specifications such as the logit, $p_{i}(k)=\frac{e^{A(k)}}{\sum e^{A(t)}}$, result in probabilities invariant to the addition of a constant into each of the $A(k)$ terms which would leave $\gamma$ unidentified. The power specification defined in equation 4 is not invariant to the addition of constants ${ }^{7}$. This is what leads to the technical identification of $\gamma$. Empirically this will be weaker, of course, but both parameters are identified. Since neither the logit or power probabilistic specification is "right" the question will be whether the power specification is empirically "close enough". That can only be judged by examining the results from applying the model.

The model of bidder behavior described in the preceding section can be transformed into an econometric model for estimating the parameters of the value function by using an objective function as seen in equation $5^{8}$. This specification is the form of the objective function used for the field data application. $\rho_{k}$ is used to denote the probability that a bidder will be predicted to choose to place a bid on item $k \in[1,5]$ or choose to withdraw from the auction, $k=6$. The latter should happen when there is no surplus available for any items in the auction for that bidder. $\rho^{*}$ is the probability with which the bidder was predicted to bid on the item they actually did bid on in that period. The loss function used here is not the standard log-likelihood function that is more typically used for models like

\footnotetext{
${ }^{7}$ Very simply consider adding some constant $k$ to to amounts $a$ and $b: \frac{a+k}{(a+k)+(b+k)} \neq \frac{a}{a+b}$ but $\frac{e^{a+k}}{e^{a+k}+e^{b+k}}=$ $\frac{e^{k} e^{a}}{e^{k}\left(e^{a}+e^{b}\right)}=\frac{e^{a}}{e^{a}+e^{b}}$.

${ }^{8}$ There is obviously a correction in the estimation routine for the case in which surpluses on all items are negative causing all probabilities of bidding to be zero which is not represented in the equation.
} 
this, but rather a quadratic loss function. This is necessary to avoid the "hypersensitivity" problem as described in ?) and ?) since this will be especially problematic in this case due to the fact that many of the predicted probabilities will be close to 0 and 1 . The log-likelihood function can induce some strange results due to its differential treatment of underprediction of low probability events from underprediction of high probability events and in particular the way it deals with events predicted to occur with zero probability.

$$
\begin{gathered}
\max _{\gamma_{i}} \sum_{t=1}^{T}\left[2 \rho^{*}(t)-\sum_{j=1}^{6} \rho_{j}^{2}\right] \\
\rho_{k}=\left\{\begin{array}{cll}
\frac{\left(\max \left(\gamma_{i} m(K)+\beta_{i}(m(k)-m(K))-p_{t}(k), 0\right)\right)^{\lambda_{i}}}{\left.\sum_{l=1}^{5}\left(\max \left(\gamma_{i} m(K)+\beta_{i}(m(l)-m(K))-p_{t}(l)\right), 0\right)\right)^{\lambda_{i}}} & \text { if } \quad k \in[1,5] \\
1-\sum_{l=1}^{5} \rho_{l} & \text { else }
\end{array}\right.
\end{gathered}
$$

Although the model is used here with a very simple 2 parameter value function in which there is only one characteristic that differentiates items, significantly more complex value functions could be used. The one used here was chosen because it seemed as if it would be a reasonable characterization of the values for bidders in the UK $3 \mathrm{G}$ auction. Such a simple function is not going to be at all worthwhile for examining auctions such as those held in the US that have licenses that are both horizontally and vertically differentiated. It is possible that these more complex situations can be examined with this methodology by designing more appropriate value functions, but this has not yet been investigated.

\subsection{Equilibrium Prices}

As part of our analysis, it will be necessary to be able to make equilibrium price predictions. In this context, equilibrium occurs at a vector of prices in which no bidder who is not a provisional winner has a non zero surplus (above the increment requirement). Obviously many equilibria of this sort exist, but the only equilibrium that we will study systematically is the efficient equilibrium.

For an example on how to actually perform this calculation we will use the values used in the experiments that are found in table 2. The bidders have been represented in table 2 in an ordered fashion, with the bidder who values items the most as bidder 1 and the bidder who values them least as bidder 12 . This is done for convenience. In the experiments, bidders were identified by random numbers between 501 and 512 such that bidder 501 did not necessarily correspond to bidder 1 in table 2 . For clarity, bidders will be referred to by their number in this table rather than their bidder id from the experiments.

The displayed ordering allows for a convenient way to calculate equilibrium prices. They can be found by finding the price at which the last excluded bidder is just willing to be excluded. In the case used in the experiments with 12 bidders and 4 items of each type, this means the price of the B items is set at the price which just makes the ninth bidder prefer to take his outside option. This is so since bidder 9 will prefer to bid on any B item below this price rather than take his outside option, but prefer the outside option to bidding on any B 


\begin{tabular}{lccc}
\hline \hline Bidder Number & Value A & Value B & Outside Option \\
\hline \hline 1 & 8,000 & 6,800 & 2,500 \\
\hline 2 & 7,660 & 6,511 & 2,394 \\
\hline 3 & 7,320 & 6,222 & 2,288 \\
\hline 4 & 6,980 & 5,933 & 2,181 \\
\hline 5 & 6,640 & 5,644 & 2,075 \\
\hline 6 & 6,300 & 5,355 & 1,959 \\
\hline 7 & 5,960 & 5,066 & 1,863 \\
\hline 8 & 5,620 & 4,777 & 1,756 \\
\hline 9 & 5,280 & 4,488 & 1,650 \\
\hline 10 & 4,940 & 4,199 & 1,544 \\
\hline 11 & 4,600 & 3,910 & 1,438 \\
\hline 12 & 4,260 & 3,621 & 1,331 \\
\hline \hline Equilibrium Price & $\mathbf{3 , 8 3 4}$ & $\mathbf{2 , 8 3 8}$ & $\mathbf{N} / \mathbf{A}$ \\
\hline \hline
\end{tabular}

Table 2: Bidder values used in experiments.

items above this price. The price for the A items is set by finding the price at which bidder number 5 is just indifferent to winning a $\mathrm{B}$ item to an $\mathrm{A}$ item, given the already determined equilibrium price of the $\mathrm{B}$ items. If there are any $\mathrm{A}$ items priced below this point, bidder 5 will prefer to bid on them rather than a B item, in equilibrium. These calculations are summarized in equations 6 and 7 the actual equilibrium prices are listed at the bottom of table 2 .

$$
\begin{aligned}
& p_{B}^{*}=V_{9}(B)-O_{9} \\
& p_{A}^{*}=V_{5}(A)-\left(p_{B}^{*}-V_{5}(B)\right)
\end{aligned}
$$

\subsection{Auction Duration}

The two fundamental principles lead naturally to a model for predicting auction duration based on opening prices, the minimum bid increment and bidder values. The first step in making predictions of auction duration requires obtaining estimates of closing prices based upon the estimated values. Once these are obtained, the predicted maximum number of bids for each license can be computed by using the following formula:

$$
s_{k, e}=(1+M)^{b_{k}} s_{k, 0}
$$

where $s_{k, e}$ is the predicted equilibrium price for item $k, M$ is the minimum bid increment (0.05 in the experiments), $b_{k}$ is the number of bids and $s_{k, 0}$ is the starting price of item $k$. The opening price, $s_{k, 0}$ and the increment, $M$, are known, with $s_{k, e}$ estimated the implied number of bids can be solved for. 
It is difficult to translate predictions on the number of bids that should be received in a continuous auction to a clock-time based time to complete as this requires modeling the time it takes a bidder to submit a bid. When running multiple field auctions of similar types, better estimates of time to complete can be obtained over time by getting estimates of the distributions of bid increments bidders use in those auctions as well as the time it takes for a bidder to submit a bid. These can then be combined to predict auction duration in future auctions. Translating predicted number of bids into a predicted number of rounds runs into similar difficulties. Consequently, in order to make our comparisons between model predictions and empirical results precise, we will present them both in terms of number of new high bids.

\section{Experiments}

The first step of analysis involves testing the theory against experimental data. The previously described model involves many maintained hypotheses including those related to preferences, bidding behavior, price equilibration, the nature of the equilibrium and even the structure of the errors that appear in the bidders choice behavior. Any of these assumptions could be dramatically in error. The purpose of the experiments is to determine the extent of that error or the degree to which the hypotheses are valid as well as the impact on the likelihood of success of the estimation technique.

\subsection{Design and Conduct}

There were a total of 6 auctions run for this study in four separate sessions. In the fourth session, three separate auctions using different subjects were run independently but at the same time. All 6 auctions were run as continuous Simultaneous Ascending Auctions using the rules explained in section 3.

All of the auctions were run with fundamentally the same structure although there were a few minor differences across some of the auctions as summarized in table 3 . In auctions 1-5, there were 12 bidders competing for 8 objects. There were two types of objects, type $\mathrm{A}$ and B, with four of each type. Each bidder was allowed to win at most one item in the auction and each bidder had the same value for all items of a given type. In auction 6 , there were 8 bidders competing for 6 objects, three of each type.

The bidder values for these auctions were generated in accordance with the value function described in section 4 . Items of type A were assumed to possess 40 units of the crucial characteristic and type B items 34. Each bidder possessed a different per unit value for the items. Bidder 1 valued the items at a value of 200 francs per unit and the value for other bidders decreased by 8.5 francs for bidder 2, 17 for bidder 3 and so on ${ }^{9}$. Bidders who did

\footnotetext{
${ }^{9}$ The fact that values were not constructed from a probability distribution is a deviation from standard auction experimental procedure. In this case, the particular distribution of the values had no theoretical impact on the model we were testing and therefore it was considered preferable to use defined values to allow
} 


\begin{tabular}{ccccc}
\hline \hline $\begin{array}{c}\text { Experiment } \\
\text { Date }\end{array}$ & $\begin{array}{c}\text { Number of Each Item } \\
\mathbf{A}(m(a)=40)\end{array}$ & $\mathbf{B}(m(B)=34)$ & $\begin{array}{c}\text { Number of } \\
\text { Bidders }\end{array}$ & $\begin{array}{c}\text { Starting } \\
\text { Prices }\end{array}$ \\
\hline \hline $1-6 / 08 / 2000$ & 4 & 4 & 12 & $2100 / 1800$ \\
\hline $2-6 / 12 / 2000$ & 4 & 4 & 12 & $2100 / 1800$ \\
\hline $3-6 / 22 / 2000$ & 4 & 4 & 12 & $1000 / 1000$ \\
\hline $4-6 / 29 / 2000$ & 4 & 4 & 12 & $1000 / 1000$ \\
\hline $5-6 / 29 / 2000$ & 4 & 4 & 12 & $1000 / 1000$ \\
\hline $6-6 / 29 / 2000$ & 3 & 3 & 8 & $1000 / 1000$ \\
\hline
\end{tabular}

Table 3: Details of experiment sessions.

not win an item in the auction were paid an amount indicated by their outside option value, $O_{i}$, which was equal to a fraction of their value for a type A item. The precise equations for determining the values for each bidder are given by equations 9-11. The actual values are listed in table 2. These values are denominated in francs and translate into dollars at the rate of 100 francs to $\$ 1.00$. For auction 6 , in which only 8 bidders participated, bidder profiles corresponding to $2,6,11$ and 12 were not used. Notice that since bidder identities corresponding to 2, 6, 11 and 12 were not assigned in session 6 which was run with 8 bidders and 6 items, bidders 9 and 5 were still the marginal bidders and therefore equilibrium prices are the same in this auction as the others.

$$
\begin{gathered}
v_{i}(A)=40 *(200-(i-1) * 8.5) \\
v_{i}(B)=34 *(200-(i-1) * 8.5) \\
O_{i}=v_{i}(A) / 3.2
\end{gathered}
$$

The experiments were conducted by recruiting mostly undergraduate students at the California Institute of Technology to participate in a computerized experiment. The subjects were brought into the lab and were first given an introductory instructional sheet to read that explained the general rules of the experiment. The subjects were then asked to log into a practice auction system and lead through an explanation of the interface and auction rules according to a Verbal Instruction Script. Before proceeding into the experiment, subjects were asked to complete a quiz that asked questions aimed at making sure the subjects understood the payoff rules and the system interface. Both the instruction sheet and the quiz can be found in the appendix.

\subsection{Results}

There are three types of results from the experiments that need to be examined. The first are benchmarks of the auctions performance in terms of efficiency and time to completion. The second set of results will determine how well the behavioral rule does in predicting the

for easy comparability across sessions. 
choices made by the subjects. The last set of results will examine the performance of the econometric models in estimating the true values of the subjects.

\subsubsection{Efficiency and Final Prices}

Result 1: Final prices are close to the efficient equilibrium (set at margin by outside option) and deviations can largely be attributed to rare major bidder errors or the minimum increment requirement.

Figure 1 presents the closing prices from all experiment sessions in a histogram with solid lines indicating where the equilibrium prices are and dotted lines indicating intervals corresponding to one bid increment above and below the equilibrium prices. The figure shows that there are only a few items whose prices ended up being different from the equilibrium values by more than can be accounted for by the use of a minimum bid increment ${ }^{10}$. The average price of all A items is statistically indistinguishable from the equilibrium level. The overall average price on A items is 3857 while the predicted price is 3834 . The resulting t-statistic of a test that the difference between the two is equal to zero is 0.3762 with a p-value of 0.7104 . The results of a Wilcoxon signed-rank test are a Z-statistic of -0.5628 and p-value of 0.5736 . For the $\mathrm{B}$ items, the average realized price is 2856 , the equilibrium price is 2838 , and the corresponding t-statistic is 0.5809 , p-value 0.5672 and a Wilcoxon $\mathrm{Z}$ of 0.2587 , p-value of 0.7958 . It therefore seems reasonable to conclude that the predictive power of the equilibrium price setting mechanism is quite strong. Although mistakes by individual bidders can affect the actual prices, the mechanism is even robust enough to account for the closing prices once such mistakes are factored in.

The fact that prices are so near the efficient equilibrium prices suggests the second result. The system is efficient by any standards with the agents with the highest valuation acquiring the appropriate items and the agents with the low valuations excluded. The pattern is summarized by the next result.

Result 2: Efficiency exceeds baseline and is often near 100\% (Those who should get items get them and those who should not, do not.) Deviations are again largely attributable to increment requirements and occasional major mistakes.

The bidder values in table 2 were setup such that in the efficient allocation bidders 1-4 should win items 1-4, bidders 5-8 should win items 5-8 while bidders 9-12 should end up taking their outside option. 19 of the 46 items auctioned did go to non-optimal bidders, but typically these misallocations were quite minor and resulted from interactions between the slight discrepancies between the actual prices and the equilibrium prices combined with the minimum bid increment requirement. Further, only twice did bidders of types 9-12 end

\footnotetext{
${ }^{10} \mathrm{~A}$ closer inspection of the data reveals that those prices that do not fit in these bounds are predominantly from experiment 2 and were the result of a serious mistake by one bidder and the ripple effects to other items.
} 


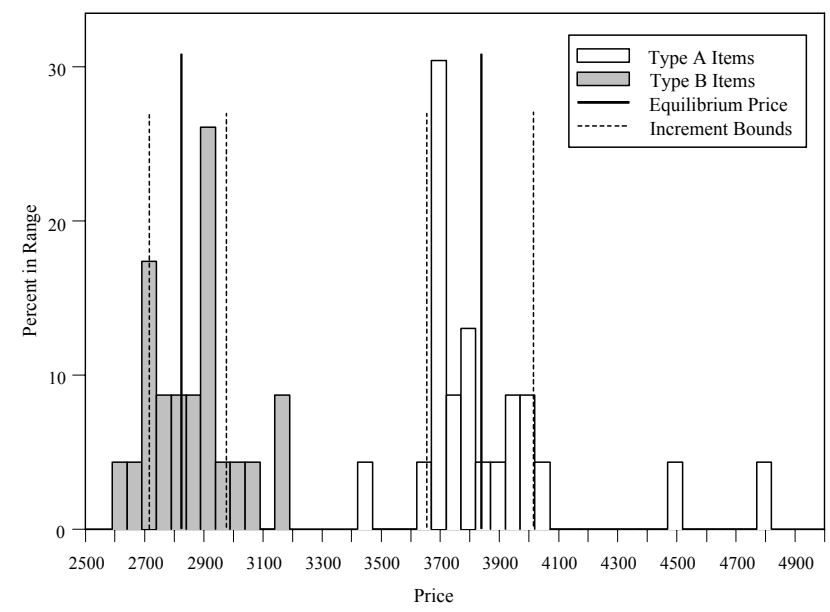

Figure 1: Histograms of closing prices. Equilibrium prices are represented by solid lines. Dotted lines represent +/- one bid increment around equilibrium prices.

\begin{tabular}{lllllll}
\hline \hline Experiment & $\mathbf{1}$ & $\mathbf{2}$ & $\mathbf{3}$ & $\mathbf{4}$ & $\mathbf{5}$ & $\mathbf{6}$ \\
\hline \hline Actual Efficiency & 0.994 & 0.977 & 0.996 & 0.997 & 0.990 & 0.995 \\
\hline Baseline Efficiency & & & 0.893 & & & 0.932 \\
\hline
\end{tabular}

Table 4: Actual efficiency for each auction compared with baseline efficiency. Baseline efficiency is the expected efficiency if items were assigned randomly.

up winning items and one of those was due to an already discussed egregious error on the part of the bidder.

The actual efficiency scores for each experiment can be found in table 4 . The maximum potential value was calculated by adding the potential value in equilibrium with bidders 1-4 winning items 1-4 and bidders 5-8 winning items 5-8. The value of the outside option for other bidders was excluded from the value of the auction. The realized value was calculated by adding the actual value for each winning bidder, again ignoring outside option values of non-winning bidders. As seen in the table, all of the efficiencies are close to 1 and all but experiment 2 are within .01 of being right at 1 .

These scores can be compared to a baseline of achievable efficiency that would be obtained if the items were randomly assigned. In the 8 item auctions, this baseline is 0.893 and in the 6 item case it is 0.932 . Consequently there is a definite improvement over a random allocation achieved by the auction and although the improvement may not seem large, the reason for this lack of a larger difference should be expected to make significant 


\begin{tabular}{lllllll}
\hline \hline Experiment & $\mathbf{1}$ & $\mathbf{2}$ & $\mathbf{3}$ & $\mathbf{4}$ & $\mathbf{5}$ & $\mathbf{6}$ \\
\hline \hline \# of Bids & 69 & 57 & 135 & 136 & 112 & 50 \\
\hline \# of Jumps & 5 & 18 & 21 & 28 & 21 & 16 \\
\hline Latest Jump & 11 & 55 & 132 & 122 & 92 & 37 \\
\hline \# Prices Set & 0 & 2 & 0 & 0 & 1 & 2 \\
\hline
\end{tabular}

Table 5: Summary of jump bid activity in experiments.

differences more difficult to obtain. The baseline efficiency is so high because there are not many excluded bidders and their values are in general not more than a bid increment or two less than the lowest winning bidders. By spacing the values so closely, it would not have taken bids that were terribly irrational on the part of the excluded bidders to win an item. One could easily imagine the improbable level of precision that would be required in constructing bids in single round sealed bid auctions that would lead to similar improvements in the efficiency scores over random allocation. The fact that bidders 9-12 in general did not win items is a testament to the robust nature of the price setting mechanism in these auctions and the efficiency they can achieve.

A claim exists in the literature, summarized in ?), that SAAs have an Achilles heal in that they allow for bidders to place "jump bids" or bids in excess of the minimum required increment. They argue that this leads to prices far in excess of equilibrium prices and can lead to significant inefficiency. There is little evidence for an effect of this nature in these auctions.

Observation 1: Jump bids are observed but their primary impact is on speed of auction, not final prices or allocation.

Table 5 contains a summary of the jump bid activity observed in the experiments. To be very conservative about defining a jump bid, these numbers were constructed by defining a jump bid as any bid that is greater than $7.5 \%$ of the previous bid. The table lists the number of total bids as well as the number of jump bids for each experimental auction. Jump bids by this definition comprise as few as $7 \%$ of the bids in an auction to as much as $32 \%$. The table also lists the last bid in the auction that was a jump bid as well as the number of final prices set by jump bids. There were a few jump bids that did result in the bidder winning the item, but as can be seen from the efficiency and price results reported previously, these had generally minor effects on both.

Figure 2 shows a more detailed picture of the jump bid activity in the auctions. This graph depicts the percent of the jump bids that were made in each auction as a function of the percent of the auction that has been completed. By the midpoint of the auctions, between 60 and $100 \%$ of the jump bids that will be made in these auctions have been made. Right after the midpoint of the auction, we can see that most are clustered in the $70-80 \%$ range. This shows that most of the jump bid activity occurs early in the auction, although a few do show up later. This graph also contains a line describing the jump bid activity in 


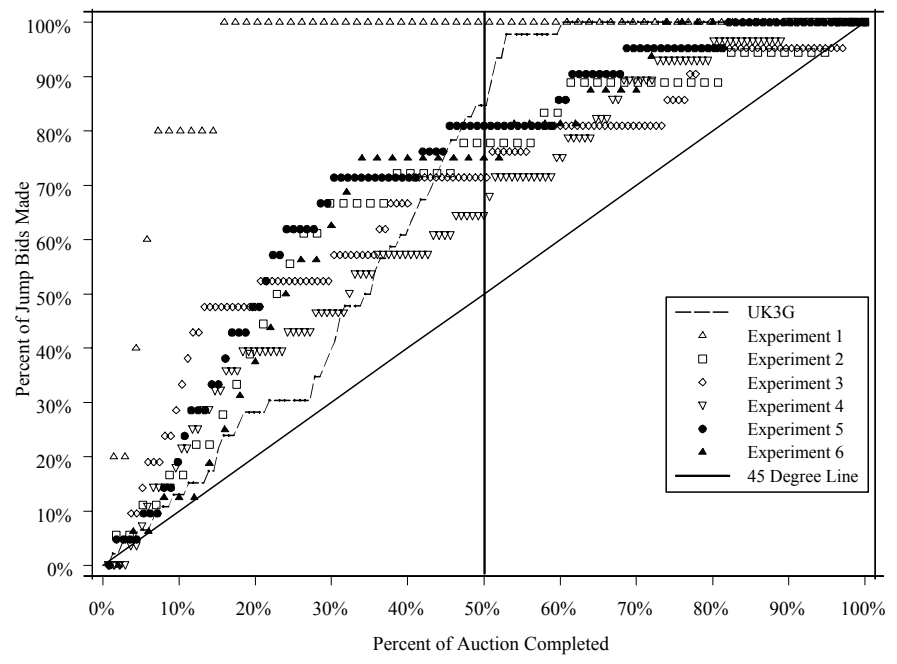

Figure 2: Out of the total number of jump bids that were made in each auction, each line shows the percentage that had been made at each point during the auctions.

the UK3G auction that will be discussed in more detail later.

Result 3: The number of bids fall short of the maximum number due to jump bids, which seem to have as a purpose, speeding the auction.

Table 6 compares the actual number of bids to the maximum number of bids for each auction. Not surprisingly, the actual number of bids is always lower. The reason they are typically so much lower is that not all of the bids were at the minimum level and this is indicated in the table by the average increment being, at times, significantly above 1.05. Most of the bids, however, were right around 1.05 as indicated by the medians

\begin{tabular}{lllll}
\hline \hline Experiment & Actual & Max Bids & Average Inc & Median Inc \\
\hline \hline 1 & 69 & 87 & 1.059 & 1.051 \\
\hline 2 & 57 & 87 & 1.096 & 1.056 \\
\hline 3 & 135 & 196 & 1.080 & 1.051 \\
\hline $4-1$ & 136 & 196 & 1.075 & 1.053 \\
\hline $4-2$ & 112 & 196 & 1.091 & 1.053 \\
\hline $4-3$ & 50 & 147 & 1.185 & 1.053 \\
\hline
\end{tabular}

Table 6: Time to complete for each auction. 
being almost exactly $1.05^{11}$. By comparing these results with the closing price results, it becomes apparent that although jump bidding is used by bidders in ascending price auctions, their primary use seems to be to speed the auction along while having little impact on closing prices. Many seem to try to claim that such jump-bidding behavior is a signalling phenomenon as described in ?), for affiliated values, or ?), for private values, but even a very casual comparison of the predictions of the models in those papers to the data should indicate that the observed behavior is not well described by signalling. Signalling would involve submitting jumps of a very large size to signal other bidders to drop out either because the jumping bidder has a value too high to compete with, ?), or because it would be too costly to continue bidding against them, ?). Jumps of this size are not observed and it would be difficult to explain in the context of these models why a bidder who has "signalled" with 10-15 small jumps in previous rounds to no effect would continue doing so or for that matter why someone would believe that a bid of $7.5 \%-10 \%$ above the previous high bid when the minimum increment is $5 \%$ would scare any serious other bidders away. Further investigation of the nature of jump bids in ascending auctions can be found in ?).

\subsubsection{The Reliability of the Principle of Surplus Maximization}

Evaluation of the model is difficult since there is not a rigorous criteria for judging the absolute level of performance of the model and because there is no known suitable alternative model to use in comparing relative performance levels. The results below summarize our attempts to identify the magnitude, nature and source of any deviations between the model predictions and the observed behavior.

Result 4: The Principle of Surplus Maximization can be used to generate predictions of which item a bidder will place a bid that have an overall accuracy rate of 50\%. Much of the error of the model can be attributed to (i) bids placed on identical items as opposed to the one with the highest surplus and (ii) small cost of errors to the bidder. Using the model to predict the class of item bid on is accurate $69 \%$ of the time with the "errors" occurring when the surplus differential is small. ${ }^{12}$

Since we know the values the subjects had during the experiments we can use them to predict which object they will bid on each time they bid. Doing so yields a $50 \%$ accuracy rate when predicting which among the 8 objects a bidder will bid on. From the "wrong" choices that bidders made, it is possible to compute how much they lost by bidding on the object that did not have the highest surplus attached to it. In most of the cases, the lost or foregone surplus was less than $\$ 1$ and the overall distribution displays a standard

\footnotetext{
${ }^{11}$ The reason the medians are not exactly 1.05 is due to the fact that minimum accepted bids were rounded to the nearest ten's value. Consequently most of the actual bid increments were things like 1.049, 1.051 and 1.052 .

${ }^{12}$ To conserve space most of the detailed support for this result has been eliminated, but is still available in an extended version of the paper available from the authors.
} 


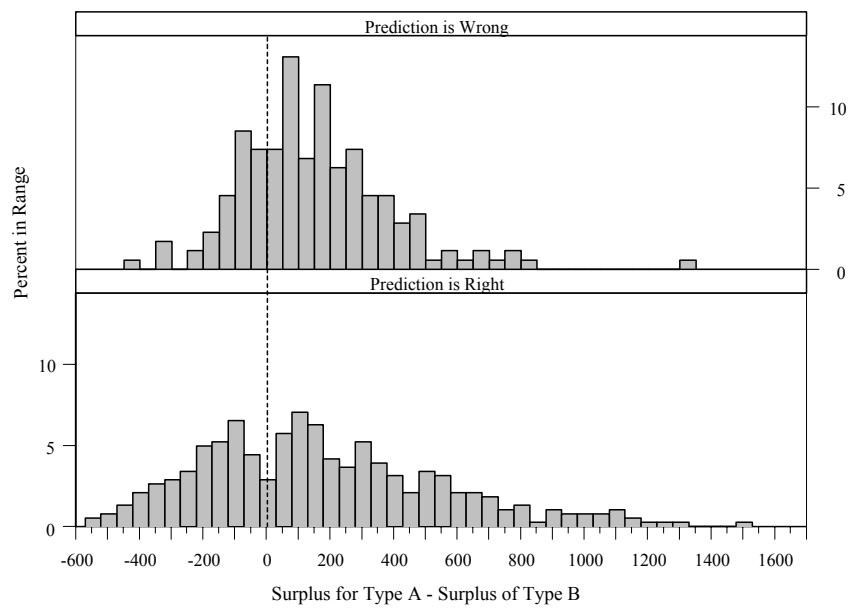

Figure 3: Histograms of difference in surplus between bidding on type A items versus type B items for all bids placed in experiments split into cases in which model prediction is correct and when it is not.

exponential decay pattern with the highest peak of the observations of loss being close to 0 with a rapid decay setting in soon after.

Due to those results and the speed with which subjects were submitting bids one might propose that they looked generally to see whether A items or B items generated more surplus and bid on one from the group that did so. Predicting which among the two groups the subjects would bid on yields a $69 \%$ accuracy rate. In some sessions the accuracy rate was above $80 \%$. If one computes the actual surplus differential that existed for every bidder "mistake", $S D_{t}=\left(v_{i}(A)-\bar{p}_{t}(A)\right)-\left(v_{i}(B)-\bar{p}_{t}(B)\right)$, and compares this with the surplus differential for "correct" bids, then two regularities are observed. First, the mean of the distribution of surplus differentials when the prediction is wrong is statistically significantly lower than when the prediction is correct. Second, figure 3 contains the histograms of values of the raw surplus differential for when bidders made the "right" bid and when they made the "wrong" bid. Notice that when bidders make the unpredicted choice, the distribution has a single peak almost exactly at 0 and the distribution is relatively tight. When the model predicts correctly, there is actually a depression around 0 and then two peaks on either side and the tails of the distribution are longer and fatter. This indicates that when the surplus differential is approximately 0 , bidders are more likely to make a mistake but as the surplus differential gets larger, mistakes decrease. This is the error pattern predicted by a model of probabilistic choice. 


\begin{tabular}{lllllllllllll}
\hline \hline Bidder & $\mathbf{1}$ & $\mathbf{2}$ & $\mathbf{3}$ & $\mathbf{4}$ & $\mathbf{5}$ & $\mathbf{6}$ & $\mathbf{7}$ & $\mathbf{8}$ & $\mathbf{9}$ & $\mathbf{1 0}$ & $\mathbf{1 1}$ & $\mathbf{1 2}$ \\
\hline \hline \# of Estimates & 0 & 4 & 2 & 4 & 2 & 4 & 5 & 4 & 4 & 3 & 1 & 1 \\
\hline
\end{tabular}

Table 7: Breakdown of which bidders yielded bid histories that resulted in meaningful parameter estimates.

\subsubsection{Results of Value Estimation}

As found in the previous section, the average price of the A and B items worked very well in terms of predicting which one a bidder will bid on. Consequently instead of having the model predict which among the 8 items our bidders will bid on, the model will just be set up to predict whether they will bid on an item of type A or of type B. For the price of a type A item we will use the average of the prices of all units of that type and the same for B items.

The version of the value function used in the experiments is a one parameter function that expresses the bidders value in terms of francs per $\mathrm{MHz}$ as represented by the parameter $\gamma_{i}$. The loss function maximized here is similar to equation 5 , but simplified to two items and no withdrawal decision. Since we do know the true values for $\gamma_{i}$, we can compare the estimates, $\widetilde{\gamma}_{i}$ to the real values as is done in table 8 . In conducting the estimations, bounds were placed on the parameters of $\gamma_{i} \in[80,230]$ and $\lambda \in[1,20]$. The main reason for using the bounds was to aid in the optimization process. Many of the bidders in the experiments had their values estimated on one of the bounds. These were typically bidders of type $1-3$ who only bid on type A items or bidders 10-12 who dropped out early and only bid on type B items. For the bidders who only bid on A items, left unconstrained, the optimization process would have arrived at very large and potentially infinite values for $\gamma_{i}$. Another use for the bounds therefore was to eliminate such obviously pathological estimates. This points out one weakness of this model which is that in order to generate accurate value estimates, bidders must be observed bidding on different objects and switching in a systematic manner. If such behavior is not observed, this technique will not be able to generate accurate value estimations.

To further emphasize this point, table 7 gives a breakdown by bidder number of how many of each type we were able to recover meaningful parameter estimates from. This shows quite clearly that the only bidders we were typically able to recover parameters from were those with intermediate values such that they would be induced to switch between bidding from one type of item to another. This will become more important in the discussion of the field results later.

The results contained in table 8 lead to the following result:

Result 5: For 50\% of those bidders who reveal information about their values through their bidding behavior, parameter estimates are obtained that are statistically indistinguishable from their true parameters.

There were a total of 68 bidders in the experiments and interior parameter estimates were 


\begin{tabular}{lcccc}
\hline \hline Experiment & Average of $\left|\widetilde{\gamma}_{i}-\gamma_{i}\right|$ & Median & Standard Dev & \% Correct Preds \\
\hline \hline 1 & 15.0 & 11.5 & 16.1 & 0.83 \\
\hline 2 & 54.3 & 49.5 & 25.1 & 0.83 \\
\hline 3 & 33.4 & 23.0 & 31.1 & 0.78 \\
\hline 4 & 31.1 & 23.7 & 24.5 & 0.87 \\
\hline 5 & 35.3 & 20.6 & 29.9 & 0.78 \\
\hline \hline Combined & 41.8 & 43.8 & 14.3 & 0.75 \\
\hline \hline
\end{tabular}

Table 8: Comparison of esitmates of $\gamma_{i}$ to the known values for those bidders not estimated on bounds.

found for 32 of them. This means that roughly half of the bidders revealed useful information about their values through their bidding behavior. Table 8 compares the absolute difference between the estimated and actual parameters for those bidders for which an interior estimate was found. These results show that the average difference between the estimated and actual values of $\gamma_{i}$ is around $34.1^{13}$. To put this in the proper scale, remember that the actual values of $\gamma_{i}$ range from 200 for bidder 1 to 106.5 for bidder 12 . If t-tests are conducted to test the hypothesis that the estimated and real parameters are equal, this hypothesis can not be rejected for $50 \%$ of those bidders whose parameters are estimated inside of the bounds at a $5 \%$ significance level. Thus for at least half of those bidders who engage in the switching behavior necessary to convey information about their values, we are able to estimate their value parameters very precisely. For the other $50 \%$ of these bidders, some of the estimates turn out quite imprecise while others just miss the $5 \%$ significance mark.

It should be noted that many of those bidders who fail the significance test or for whom meaningful parameters can not be recovered, submitted very few bids in the auction. In fact the average number of bids submitted by bidders for whom parameter estimates were not recoverable was 7.00 , while the averages were 8.34 for all bidders with recoverable parameters and 10.07 for those $50 \%$ whose parameters were estimated precisely. Not surprisingly, then, this indicates that the quality of the estimates tends to improve with the number of observed bids. The interesting point though, is how few bids are needed before estimates of reasonable accuracy can begin to be made.

Result 6: The internal consistency check results in a model accuracy of about $81 \%$ of the bids accurately predicted.

This result is shown in the last column of table 8 . The predictions were generated by taking the estimated parameters and then making deterministic predictions that the bidder would bid on the item that would yield the most surplus. This can be taken as an indication

\footnotetext{
${ }^{13}$ If the bidders estimated on the bounds are included the aggregate results are average of 45.9, median of 41.7 and standard deviation of 31.1. As discussed previously though, these results are controlled by the choice of bounds and so are somewhat arbitrary.
} 
that the bidders do appear to bid in a systematic manner that is generally consistent with the principle of surplus maximization and that in doing so, they are revealing information about their values that this econometric technique can take advantage of.

One consequence of the noted small size of the bid histories for many of the bidders is that we felt trying to obtain partial history estimates from the experimental data would not be feasible as this would involve trying to make inferences from less than 3-4 data points in most cases. Consequently, we will present no results on partial data set estimates in this section, although we will be able to do so for the field study.

\section{Field Data}

\subsection{Description of Data Set}

The motivation for this project was to develop a model of bidder behavior in Simultaneous Ascending Auctions that could be applied to field data. Due to its strategic simplicity, the field data set that we will investigate is taken from the U.K. auction for licenses to provide third generation wireless services (also called the U.K. UMTS auction). In this auction there were 5 licenses up for sale in a simultaneous multiple round auction. It began on March 6, 2000 and lasted 150 rounds, closing on April 27, 2000. The total revenue for this auction was $£ 22.477$ billion or approximately $\$ 33.2$ billion ${ }^{14}$.

The licenses in this auction can be divided into three groups. The A block license was the largest license and contained $35 \mathrm{MHz}$ of spectrum. The B block license contained 30 $\mathrm{MHz}$ of spectrum while blocks $\mathrm{C}, \mathrm{D}$ and $\mathrm{E}$ all contained $25 \mathrm{MHz}$. For most purposes, the only difference between these licenses was the amount of spectrum they contained. Prior to the auction, some bidders expressed the opinion that only $25 \mathrm{MHz}$ was necessary to provide service and that the extra 5 or $10 \mathrm{MHz}$ in the A or B block was not necessary. This is the reason for using the two parameter version of the value function, equation 3 .

There were 13 bidders participating in the auction and each bidder was allowed to win at most one license in the auction. Four of these bidders held existing licenses to provide cellular or PCS service and were barred by the auction rules from bidding on the A block license. This was done in an attempt by the Radiocommunications Agency in the UK to ensure that at least one new entrant was able to enter the wireless communications market in the UK as a result of the auction.

The results of the UK $3 \mathrm{G}$ auction are contained in table 9 including the opening price, closing price and winning bidder for each license. In the end, the four existing operators all won one of the B-E licenses and the one lone new entrant winner, won the reserved A block license. It is interesting to note that although the A block license is the largest of the five, it sold at only the second highest price and its price is significantly less than the price for license B while not being much higher than the prices for C-E. One might suspect that this would cause a problem for the simple value function that suggests bidder values are

\footnotetext{
${ }^{14}$ Exchange rate was approximately 1 US dollar to .677227 British Pounds on April 27, 2000.
} 


\begin{tabular}{lccc}
\hline \hline License & $\begin{array}{c}\text { Opening Price } \\
\text { (in hundreds of millions) }\end{array}$ & $\begin{array}{c}\text { Closing Price } \\
\text { (in hundreds of millions) }\end{array}$ & Winning Bidder \\
\hline \hline $\mathrm{A}$ & $£ 1.25$ & $£ 43.847$ & TIW \\
\hline $\mathrm{B}$ & $£ 1.07$ & $£ 59.640$ & Vodaphone \\
\hline $\mathrm{C}$ & $£ 0.89$ & $£ 40.301$ & BT3G \\
\hline $\mathrm{D}$ & $£ 0.89$ & $£ 40.036$ & One2One \\
\hline $\mathrm{E}$ & $£ 0.89$ & $£ 40.950$ & Orange \\
\hline
\end{tabular}

Table 9: Summary results of UK 3G auction.

\begin{tabular}{lccccc}
\hline \hline \multicolumn{1}{c}{ Bidder } & A & B & C-E & Total & Round Withdrawn \\
\hline \hline 3GUK & 4 & - & 60 & 64 & 95 \\
\hline BT3G & - & 33 & 74 & 107 & - \\
\hline Crescent & - & - & 82 & 82 & 94 \\
\hline Epsilon & - & - & 58 & 58 & 98 \\
\hline NTL Mobile & 25 & - & 33 & 58 & 150 \\
\hline One.Tel & 2 & - & 79 & 81 & 101 \\
\hline One2One & - & - & 105 & 105 & - \\
\hline Orange & - & 18 & 27 & 45 & - \\
\hline Spectrum Co. & 21 & 5 & 22 & 48 & 97 \\
\hline Telefonica & 6 & 1 & 43 & 50 & 133 \\
\hline TIW & 12 & 5 & 52 & 69 & - \\
\hline Vodafone & - & 43 & - & 43 & - \\
\hline Worldcom & 5 & - & 57 & 62 & 121 \\
\hline
\end{tabular}

Table 10: Number of bids placed by each bidder on each item and round that they withdrew.

strictly increasing in $\mathrm{MHz}$. Since, however, the four incumbent operators were prevented from bidding on the A block license, these results do not contradict the form of the value function. One or more of the 4 incumbents could have had a value for the A block license higher than the $£ 4.5$ billion bid by TIW, but were unable to express that value due to the restrictions.

Before examining the parameter estimates it will be useful to get an idea of the bidding behavior. Table 10 shows how often each bidder bid on licenses of each type and when they dropped out of the auction. Notice that there were 3 bidders who never bid on any licenses other than $\mathrm{C}-\mathrm{E}^{15}$. These bidders are giving away very little information about their values that our approach can take advantage of until they drop out of the auction. All we will be able to do for these bidders prior to their dropout is fix a value for $\beta_{i}$ of 0 . There is one bidder, Vodafone, who does the same thing by bidding on B the entire auction but as we will see, it is possible to obtain a reasonable value estimate from this behavior. A few other

\footnotetext{
${ }^{15}$ These are Crescent, Epsilon and One2One.
} 
bidders only switch a few times ${ }^{16}$ and therefore do not reveal much information. The rest of the bidders are the ones the model should be more likely to gain some insight on during the auction. These are BT3G, NTL Mobile, Orange, Spectrum Co and TIW.

As a final note about the nature of the data, we can make one observation in regard to the impact of jump bids on the outcome of the auction:

Observation 2: As in the experiments, there were a number of jump bids, but they had no apparent impact on the outcome of the auction and the overall pattern of jump bids is similar to that observed in the experiments.

There were 355 bids in the UK3G auction that lead to new high bids. Out of those, 46 of them would be classified as jump bids using the same definition used earlier which is a bid that is more than $7.5 \%$ greater than the previous high bid. The last such bid was placed in round 91 of the auction on license C. This license received 29 more bids over the course of the rest of the auction. There were, of course, many bids placed after this point that were above the minimum required amount but most were very modestly above the minimum and it would seem strange to characterize these as true "jumps". This includes the last bid made by Vodafone to win the B license. In round 143, Vodafone placed a bid that was $2.8 \%$ above the previous high bid even though they were only required to place a bid $1.5 \%$ higher. It would seem fairly difficult to support a claim that either a bid this far in excess of the minimum increment or the much larger jumps made earlier in the auction could have had a significantly negative impact on the efficiency of the auction.

Referring back to figure 2, the second part of the observation becomes clear. The line indicating the pattern of jump bidding in the UK3G rises in manner quite similar to what was observed in the experiments indicating that most of the jump bids occurred early in the auction. This graph also shows again that there were no jump bids of significant size in the last $40 \%$ of the auction (rounds 92-150).

\subsection{Results}

There are several ways that we will examine the results from estimating the model on the field data. The first thing we will do is estimate the parameters of equation 5 on the full history of the auction for each bidder. We will compare those value estimates with the final results to determine how reasonable they appear. We will then move on to looking at how well the model can perform on partial histories of the data set. We will generate parameter estimates with only part of the data set and then compare those estimates to the final results of the auction.

All of the estimates in this section were obtained through estimating equation 5 separately for each bidder. This objective function can result in a very difficult surface to find a global maximum over, so a simulated annealing algorithm was used for the optimization ${ }^{17}$. Standard errors of the parameter estimates were computed using a jackknife procedure.

\footnotetext{
${ }^{16}$ 3GUK, One.Tel, and Worldcom.

${ }^{17}$ The version of the algorithm adapted by E.G. Tsionas for Gauss was used as the base for the algorithm.
} 
In this implementation, if a bidder places $j$ bids during the auction, estimates of the parameters were obtained using $j$ subsets of the data with each estimation leaving out one observation from the data set. The standard errors of the estimates are then the standard errors of the empirical distribution of estimates. Since the extra zeros should ultimately not matter, the prices of the licenses were normalized by dividing by 100 million as was done in table 9 to make them more manageable. All prices and parameter estimates below are reported according to this normalization. The estimates were performed with bounds on all of the parameters: $\gamma_{i} \in[0.60,20.00], \beta_{i} \in[0.00,20.00]$, and $\lambda_{i} \in[1.00,20.00]^{18}$. Therefore if a value is found for $\gamma_{i}$ of 1 , this can be interpreted as the bidder valuing spectrum at the level of $£ 100$ million per $\mathrm{MHz}$.

\subsubsection{Full Data Set Estimates}

The first test of the approach is how accurately it is able to estimate parameters for bidder value functions given the entire history of the auction. The parameters with standard errors for full history estimates are found in table 11. From the results in this table, we can find our next result:

Result 7: The model passes consistency requirements in the sense that (i) parameter estimates for only one out of the 13 bidder constitute a serious bound violation (ii) final prices are largely consistent with those predicted based on the estimated values (iii) the estimated parameters accurately predict around $78 \%$ of the actual choices made.

The first thing to notice about these estimates is that all but two of the estimates for $\lambda_{i}$ are pegged at the upper bound of 20 with virtually no variance to the estimate. Recall that this is the parameter that captures the individuals sensitivity to surplus differentials or perhaps an indication of their propensity to best respond. This result is due to the fact that many of these bidders appear to be best responding very strongly according to their estimated values, which means that $\lambda_{i}$ will be estimated at the upper bound regardless of what that value is. This cutoff of 20 was chosen simply as a reasonable upper bound as it implies a very strong degree of best responding already and raising it does little to change any of the results.

Since we do not know the true values for $\beta_{i}$ and $\gamma_{i}$ as we did in the experiments, we can not directly measure how close these come to true values. A simple consistency check is to examine the prices for the items at the point at which the bidders dropped out of the auction. These prices can give us bounds on what we should expect to find for $\beta_{i}$ and $\gamma_{i}$. This can be done simply by looking at the last bid placed by each bidder and finding values for $\beta_{i}$ and $\gamma_{i}$ that rationalize their choice.

\footnotetext{
${ }^{18}$ The bounds on $\gamma$ were imposed solely to aid in the optimization process and were constructed by finding a parameter range that resulted in no bidders being estimated on boundaries. $\beta$ was bounded below by 0 as there is no reason why extra spectrum should harm the value of a license and above by 20 to aid in the optimization process. $\lambda$ was bounded below by 1 to ensure that we obtain $\rho_{k} \in[0,1]$ and above by 20 , again just to have a reasonable upper bound cutoff. Bidders were estimated on this bound, but that is unlikely to cause a problem.
} 
The bounds are listed in table 11 as $\widehat{\beta}_{i}$ and $\widehat{\gamma}_{i}$. All numbers should be taken as upper bounds except for those underlined which are lower bounds. A comparison between the bound requirements and the estimated values for $\beta_{i}$ and $\gamma_{i}$ reveal that among 26 parameters there are several estimates found right on the bounds but bound violations are found for four parameters across 3 bidders. The first is in the estimated value of $\beta_{i}$ for Spectrum Co. as the estimated value of $\beta_{i}$ is 0.26 , but the bound restriction is $0.26=\beta_{i}<\widehat{\beta}_{i}=0.14$ which obviously does not hold. This is not, however, too damaging of a violation since Spectrum Co. was the third bidder to drop out of the auction. The second violation at first glance looks much more severe as Vodafone should have an estimated $\gamma_{i} \geq 1.58$ by the argument of these bounds but the estimate is 0.58 . This turns out not to be a real violation of the spirit of the bounds. In this case the actual restriction supposedly violated requires that the combination of the values of $\gamma_{i}$ and $\beta_{i}$ be such that $25 * \gamma_{i}+5 * \beta_{i}-57.99 \geq 0$ or the surplus from bidding on the $\mathrm{B}$ license is greater than 0 . The bound in the table was found by substituting in $\widehat{\beta}_{i}=3.71$ found through a different restriction and solving for $\gamma_{i}$. Using that value of $\beta_{i}$, this restriction does not hold, but the actual estimated values of $\gamma_{i}$ and $\beta_{i}$ do satisfy this joint restriction as $25 * .58+5 * 14.66-57.99=29.81>0$.

The only serious violation of the bounds is found for NTL Mobile. The value that they are estimated to have is the highest among the bidders in the auction by a fair margin, but they did not win an item in the auction and thus did not express this full value in their bidding behavior. They were however the last bidder to drop out of the auction causing it to close. As will be seen below, this potential overestimation of NTL's values is the main cause of some of the prediction errors that will be made off of this collection of value estimates.

The next check on the estimated values is to determine whether or not they match with the final price and allocation results in the real auction. This can be done by taking the estimated values and predicting closing prices and winning bidders as was done with the experiment values. Results are contained in table 12. The main allocation error is that NTL Mobile was predicted to win the A block license instead of TIW. TIW was, however, estimated to have second highest value for A among those eligible to win it. The difference in values was quite large as the value estimate for NTL was 98.97 and 41.84 for TIW. Looking back at table 11 we can also see that the estimated parameters for NTL had one of the worst fits and the highest standard deviation. This error also pushed One2One out of the C-E position. One2One was, however, estimated to be the last excluded bidder on licenses C-E and would have been predicted as a winner had NTL not taken the A license from TIW.

The only other inaccuracy is a rather severe underestimation of the price of the B license. There are two possible ways to explain this result. Based on these estimates, Orange was the price setting bidder while BT3G was the price setting bidder in the real auction. If we had obtained either a lower estimate for Orange's value for the C-E licenses or a higher estimate for BT3G's value for the B license, either would have resulted in a higher price prediction for the B license. Thus the error could be thought to have been derived from either estimate. 


\begin{tabular}{|c|c|c|c|c|c|c|c|}
\hline Bidder & $\gamma_{i}$ & $\beta_{i}$ & $\lambda_{i}$ & $\widehat{\gamma_{i}}$ & $\widehat{\beta}_{i}$ & Det PR & Prob PR \\
\hline 3GUK & $\begin{array}{c}0.66 \\
(0.00)\end{array}$ & $\begin{array}{c}0.00 \\
(0.00)\end{array}$ & $\begin{array}{c}20 \\
(0.00)\end{array}$ & 0.84 & 0.22 & 0.80 & 0.35 \\
\hline BT3G & $\begin{array}{c}1.61 \\
(0.00)\end{array}$ & $\begin{array}{c}0.67 \\
(0.01)\end{array}$ & $\begin{array}{c}20 \\
(0.00)\end{array}$ & $\underline{1.61}$ & 4.05 & 0.77 & 0.31 \\
\hline Crescent & $\begin{array}{c}0.73 \\
(0.00)\end{array}$ & $\begin{array}{c}0.00 \\
(0.00)\end{array}$ & $\begin{array}{c}20 \\
(0.00)\end{array}$ & 0.73 & 0.13 & 0.99 & 0.41 \\
\hline Epsilon & $\begin{array}{c}0.83 \\
(0.00)\end{array}$ & $\begin{array}{c}0.000 \\
(0.00)\end{array}$ & $\begin{array}{c}20 \\
(0.00)\end{array}$ & 0.89 & 0.09 & 0.73 & 0.37 \\
\hline NTL Mobile & $\begin{array}{l}3.71 \\
(0.56)\end{array}$ & $\begin{array}{c}0.63 \\
(0.04)\end{array}$ & $\begin{array}{c}20 \\
(4.49)\end{array}$ & $1.63^{*}$ & $0.43^{*}$ & 0.46 & 0.17 \\
\hline One.Tel & $\begin{array}{l}0.87 \\
(0.00) \\
\end{array}$ & $\begin{array}{l}0.00 \\
(0.00) \\
\end{array}$ & $\begin{array}{c}20 \\
(0.00) \\
\end{array}$ & 0.96 & 0.33 & 0.96 & 0.40 \\
\hline One2One & $\begin{array}{l}1.60 \\
(0.00)\end{array}$ & $\begin{array}{c}0.00 \\
(0.00)\end{array}$ & $\begin{array}{c}20 \\
(0.00)\end{array}$ & $\underline{1.60}$ & 4.10 & 0.99 & 0.41 \\
\hline Orange & $\begin{array}{c}2.84 \\
(0.09)\end{array}$ & $\begin{array}{l}1.21 \\
(0.04)\end{array}$ & $\begin{array}{c}20 \\
(0.00)\end{array}$ & $\underline{1.60}$ & 4.09 & 0.42 & 0.21 \\
\hline Spectrum Co. & $\begin{array}{c}0.84 \\
(0.01) \\
\end{array}$ & $\begin{array}{c}0.22 \\
(0.02) \\
\end{array}$ & $\begin{array}{c}20 \\
(0.00) \\
\end{array}$ & 0.87 & $0.14^{*}$ & 0.59 & 0.31 \\
\hline Telefonica & $\begin{array}{l}1.47 \\
(0.01)\end{array}$ & $\begin{array}{c}0.18 \\
(0.01)\end{array}$ & $\begin{array}{c}20 \\
(0.00)\end{array}$ & 1.50 & 0.76 & 0.53 & 0.26 \\
\hline TIW & $\begin{array}{l}1.66 \\
(0.01) \\
\end{array}$ & $\begin{array}{l}0.06 \\
(0.01) \\
\end{array}$ & $\begin{array}{c}20 \\
(0.00)\end{array}$ & 1.47 & $\underline{0.71}$ & 0.65 & 0.16 \\
\hline Vodafone & $\begin{array}{c}0.58 \\
(0.48) \\
\end{array}$ & $\begin{array}{c}14.66 \\
(3.39)\end{array}$ & $\begin{array}{l}17.17 \\
(3.42)\end{array}$ & $1.58^{*}$ & $\underline{3.71}$ & 1.00 & 1.00 \\
\hline Worldcom & $\begin{array}{l}1.27 \\
(0.01)\end{array}$ & $\begin{array}{l}0.00 \\
(0.00) \\
\end{array}$ & $\begin{array}{c}20 \\
(0.00)\end{array}$ & 1.36 & 0.65 & 0.87 & 0.33 \\
\hline
\end{tabular}

Table 11: Full data set parameter estimates with standard errors. $\widehat{\gamma}$ and $\widehat{\beta}$ are the implied bounds on the parameter based on dropout prices. Lower bounds are underlined, all others are upper bounds. Det PR and Prob PR represent the prediction rate of the deterministic model and the probabilistic model respectively.

\begin{tabular}{cccccc}
\hline \hline License & A & B & & CDE & \\
\hline \hline Pred Win & NTL Mobile & Vodafone & Orange & TIW & BT3G \\
\hline Actual Win & TIW & Vodafone & Orange & One2One & BT3G \\
\hline Pred Price & $£ 40.70$ & $£ 46.10$ & & $£ 40.04$ & \\
\hline Actual Price & $£ 43.847$ & $£ 59.640$ & $£ 40.301$ & $£ 40.036$ & $£ 40.950$ \\
\hline
\end{tabular}

Table 12: Predicted outcome of UK Auction from full data set parameter estimates compared with actual results. Prices are in hundreds of millions of British Pounds. 


\subsubsection{Partial Data Set Estimates}

The real test for this model is in how it is able to perform in estimating bidder values on only part of the data set. If this methodology is going to be useful during the auction to either the auctioneer, then it must be able to gain decent estimates of bidder values during the auction. For the purposes of the auctioneer we would argue that the standard for "decent" is really obtaining estimates that are of the approximate order of magnitude of the final prices as this is all that is needed by the auctioneer. By performing estimates of the parameters based on using the first 75 and then the first 100 out of the full 150 periods of the auction, we can find our next result:

Observation 3: Comparing 75 and 100 period estimates to full history estimates shows that the estimates of $\beta_{i}$ lock in correctly while the early estimates of $\gamma_{i}$ are not as precise.

To conserve space, we have omitted listing out all of the parameter estimates for the bidders, but will characterize the results. There were four bidders who dropped out of the auction between rounds 75 and 100: 3GUK, Crescent, Epsilon and Spectrum Co. It should be no surprise that the 100 period and full history parameter estimates are the same. For most of the bidders the estimated values for $\beta_{i}$ are typically fairly close over all three estimates while the estimate on $\gamma_{i}$ varies considerably more. In most cases, the reason $\gamma_{i}$ varies so much has to do with the fact that the bidders were only bidding on items C-E. When a bidder does this, the only information conveyed is that they see little value in the extra $5-10 \mathrm{MHz}$, or $\beta_{i}$ is zero, and that they think the first 25 is worth at least as much as the current price. For these bidders a reliable estimate of $\gamma_{i}$ is not obtainable until they drop out. For the bidders who engage in more switching, this is a manifestation of the relatively weak identification of $\gamma_{i}$ that was discussed earlier.

The best way to evaluate these value estimates from the point of view of the auctioneer will be to use them to generate auction closing predictions of revenue and winning bidders. These are found in table 13 and provide the support for result 8.

Result 8: The value estimates obtained using only partial data sets are able to generate auction closing predictions, that are reasonably accurate. If these predictions are modified based upon knowledge available to the auctioneer during the auction, these predictions can be significantly improved.

In examining table 13, it is clear that the winning bidder predictions remain fairly constant across all estimations, with the minor mistake of predicting NTL Mobile winning the A block instead of TIW persisting and causing a few minor mistakes in the C, D and E block predictions. In most cases, 3 out of the 5 eventual winners are predicted accurately and the 2 errors are not made by large margins when the actual estimated values are examined $^{19}$. In regard to price predictions, the errors seem a bit more problematic as the

\footnotetext{
${ }^{19}$ At the 75 period mark, there are several bidders estimated to have the same value as One2One (11.05) for C-E including TIW, Worldcom, 3GUK and Crescent while BT3G's value is estimated at 10.525. The predicted values for BT3G and One2One at the 100 period mark for C, D and E are 22.76 and 22.60 respectively. The estimated value for Worldcom is 22.89 .
} 


\begin{tabular}{cccccc}
\hline \hline License & A & B & CDE & \\
\hline \hline 75 PD Win & NTL Mobile & Vodafone & Orange & Epsilon & One2One \\
\hline 100 PD Win & NTL Mobile & Vodafone & Orange & TIW & Worldcom \\
\hline Full Win & NTL Mobile & Vodafone & Orange & TIW & BT3G \\
\hline Actual Win & TIW & Vodafone & Orange & One2One & BT3G \\
\hline 75 PD Price & $£ 13.55$ & $£ 15.12$ & & $£ 11.05$ & \\
\hline 75 PD Alternative & $£ 15.96$ & $£ 25.58$ & & $£ 21.51$ & \\
\hline 100 PD Price & $£ 23.8$ & $£ 27.12$ & & $£ 22.75$ & \\
\hline 100 PD Alternative & $£ 42.77$ & $£ 43.26$ & & $£ 38.89$ & \\
\hline Full PD Price & $£ 40.65$ & $£ 46.07$ & & $£ 40.04$ & \\
\hline Actual Price & $£ 43.847$ & $£ 59.640$ & $£ 40.301$ & $£ 40.036$ & $£ 40.950$ \\
\hline
\end{tabular}

Table 13: Predicted outcome of UK Auction from partial data set parameter estimates compared with actual results.

75 and 100 period price estimates range from $£ 11.05$ to $£ 27.12$ hundred million while the actual closing prices range from $£ 40.301$ to $£ 59.64$ hundred million. The reason for this is a definite underestimation of $\gamma_{i}$ for a large number of bidders. In general, the bidders for whom $\gamma_{i}$ is underestimated are those who are not giving away much information in their bidding activity by just bidding on C, D and E. Consequently, the bidders who will eventually be price setting bidders are estimated to have values below their true values and the result is underestimated prices.

In practice though, an auctioneer would be able to identify these problems and base more general predictions upon the values of bidders for whom more reasonable estimates can be obtained. If this is done at the 100 period mark, price estimates can be generated as $£ 42.77$ for the A block, $£ 43.26$ for B and $£ 38.89$ for C-E. These estimates are obtained by predicting that the price of $\mathrm{C}-\mathrm{E}$ will be approximately the value estimated for Orange and then finding prices for A and B that make NTL and Vodafone prefer to bid on A and B. Similar estimates made at the 75 period mark generate prices of $£ 21.51$ for $\mathrm{C}-\mathrm{E}, £ 25.58$ for B and $£ 15.96$ for A. This essentially involves assuming that at least one of those bidders who are not revealing their values will have a value in the same level as Orange, the bidder with the lowest values among those for whom a reasonable estimate is achievable. The 100 period alternative estimates are now quite precise although the 75 period alternative estimates still underestimate the final results.

These alternative estimates are important for demonstrating both the strength and weakness of this methodology. The weakness is demonstrated by the need to use an alternative prediction due to the number of poor estimates. The strength is demonstrated by the fact that in spite of this, an auctioneer who understands how to interpret the results of estimations of this sort can extract useful information as the auction is occurring. As stated in the introduction, what the auctioneer needs to know during the auction is how close the auction is to finishing. At the 100 period mark, the answer was relatively precise 
in informing the auctioneer of the scale of the final prices. Even at the 75 period mark, the information extracted would have been helpful. The reason is that the current prices in round 75 were in the $£ 1$ billion range. A careful analysis of the estimation results yields information that suggests that those bidders for whom reasonable estimates are recoverable are willing to pay at least twice that. By making a relatively mild assumption that at least a few of the bidders who have been hiding their values are willing to bid up to similar levels, the auctioneer could have seen that the auction was far from closed and would have seen no reason to begin slowing the auction down and perhaps would have wanted to speed it $\mathrm{up}^{20}$. It was in approximately round 108, however, in which the UK auctioneer actually began to slow the progress down by dropping the minimum increment from $5 \%$ to $4 \%$. This was at a time when the actual prices in the auction were roughly $2 / 3$ of their eventual totals and of the level that would have been predicted by this approach.

We should note that it is not our intention to be critical of the manner in which the UK Radiocommunication Agency ran this auction. Given the information available to them prior to the auction, their approach was likely reasonable as by most accounts they had little expectation that the prices would go so high. Our intention is to point out that for future auctioneers, they may be able to supplement any information obtained prior to the auction about closing prices with information revealed during an auction based upon a methodology similar to what is described here.

In addition to final price and allocation predictions, we can also generate predictions about auction duration using the methodology described in section 4.5. This leads us to our final result:

Result 9: The number of actual bids again falls short of the predicted maximum number of bids. This is a function of jump bidding and inaccuracies in the price predictions.

The actual number of new high bids observed in the auction was 355 . If one takes the prices predicted from the full period estimates, assuming a constant minimum bid increment of .05, the prediction is that it would take 382.53 high bids to reach the equilibrium prices. The prediction made at the 100 period mark would be 325.93 according to the straight price predictions versus 380.49 based on the alternate ones while the prices predicted at the 75 period mark would predict a total of 258.02 new high bids.

There are a couple of notes to make about these predictions. First is that they were made assuming a constant increment even though the auctioneer lowered the increment several times late in the auction. The result is that in some sense, the true predicted maximum number of bids would be slightly higher. The constant increment was used for two reasons. One is that when making the predictions from period 75 or 100, it was not known that these changes would be made. Thus if the altered increments were incorporated into the predictions it would involve using information not available at that point in the auction. The second problem has to do with the second note about these predictions which is that,

\footnotetext{
${ }^{20}$ It seems likely that one could improve the benefit of this approach by combining these estimates with a Bayesian approach based upon updating pre-auction estimates or upon a general value distribution structure that posits some overall structure to the values held by the bidders.
} 
although ideally one might like them to have been, these have not been translated into a predicted number of rounds. Consequently, it would be difficult to know when to engage the increment changes. The reason the predictions have been presented as the number of new high bids rather than rounds is that the translation into rounds is a very problematic one. The issue is that waves or cycles can develop in a probabilistic manner on licenses C-E and whether they occur or not can have a large impact on the number of rounds. In order to generate precise predictions, then, we have neglected to translate the number of bids into numbers of rounds.

In matching the predictions with the actual number of bids we see that the predictions based on final value estimates and on the alternate 100 period estimates overpredict the number of bids. This is due to the presence of the jump bids early in the auction spurring the prices on quicker than the model predicts. The 75 period and 100 period predictions are too low as a result of under predicting the final prices.

\section{Conclusion}

This study takes a step beyond the existing experimental literature. Both single item ascending price auctions and simultaneous ascending price auctions have been previously studied experimentally and the findings here in regard to efficiency and accuracy of the equilibrium price predictions are completely consistent with reports in the literature. The new results deal with an environment that is often found in the field and the development of a model of bidder behavior in these auctions that is used as a foundation for an econometric method for making value inferences and generating predictions about end of auction results. With one exception, previous experiments that do not violate convexity conventions use only additive values without restriction on the number of units purchased, a budget constraint or other feature that would force the revelation of substitutions, switches or trade-offs. By contrast this paper examines the efficiency of simultaneous ascending auctions and the possibility of modeling the dynamics under conditions where substitutions and switches can be anticipated. The overall issue is the ability to use early auction data to predict when such auctions might end and what prices will emerge. The results reported here are encouraging.

A disequilibrium model of bidder behavior is developed from two basic principles. These principles hold that individual bids will be tendered on the items that yield the highest surplus and that the bids will be the lowest possible given the rules. These can be combined with a third principle to generate final price predictions based upon bidder values which is that equilibration of the model will occur at the most efficient possible equilibria in which no bidder has a non-zero surplus. The resulting model can be used to estimate the underlying values that exist in the bidding population and from those, predict bids and the ultimate outcome of an auction.

Experimental results suggest that when needed, we can use the efficient equilibrium as a maintained assumption for predicting final prices. Experiments were used to assess the foundations of the model and they demonstrate that prices are close to those predicted by 
the efficient equilibrium (Result 1) and the results of the auctions are generally efficient (Result 2). Deviations from the efficient prices and allocation are largely attributable to increment requirements and mistakes. In particular "jump bids", which have been reported in the literature, have little or no effect on final outcome or prices and seem have a purpose of speeding the auction to a conclusion. Actual time of the auction from start to end fall short of the model's predictions (Result 3). The reason for this is jump bids (obs1). How they can be incorporated into the model to get better predictions is an open question.

The experiments also produced support for the additional underpinnings of the model. The Principle of Surplus Maximization does a good job (Result 4) by predicting accurately $50 \%$ of the individual items on which a bidder will place a bid and this prediction rate is greatly improved if it includes in the prediction, items on which the values are very close. That is, the errors of this principle are related to the value loss from its violation in that errors tend to occur when items are close in value and tend not to occur when items are farther apart in value.

Further support for the model is produced by checks on the internal consistency of value estimates. The internal consistency rests on the ability of the model to recover values that are known to the experimenter and to use those values to produce predictions of individual bids (Results 5 and 6 ). The values of all bidders cannot be recovered but the values are exactly correct for half of those that can be recovered. The accuracy of the model is further revealed by the fact that for all individuals for whom measurements can be made the accuracy of the model in predicting the item on which they bid is on average $81 \%$.

The model was applied to field data from the UK Third Generation Mobile auction. Application of the model to the experiments and to these field data has similarities. In the field data, jump bidding is again observed and it seems to have an effect of speeding the auction while having no effect on allocations. As a side note we point out that in recent field applications of this mechanism to various real estate auctions, we have continued to observe similar phenomena relating to jump bids. There is a clear pattern across these auctions, as seen in the experiments and the UK auction, that jump bidding occurs early in the auction when prices are well below expected final prices and then rarely occur late in the auction as prices approach equilibrium values.

The internal consistency of the model when applied to the field data is on the same order as the consistency when applied to the experiments. In the field, the predictions of the model based on inferred values is $78 \%$. (result 7). Of course the real challenge is predicting final values and end of auction results early in the auction. Early bidding behavior does not contain too much information about the final prices because the key parameters are not known for some agents until they start dropping out. Value estimates made from early bidding data are not stable but as the auction progresses they become more so (observation 3). About two thirds of the way through the auction the winners can be reasonably accurately predicted and with additional information available to the auctioneer, the magnitude of the final prices can as well (result 8). As in the experimental auctions, the auction duration predictions generally over predict the length of the auction 
as a result of jump bidding (result 9).

Overall the model reported here shows promise. The problem that motivated the study was to develop a model that could be used early in the auction to produce predictions about how long the auction would last and what the final prices would be. We can report substantial progress toward this goal. The model produces the desired predictions. The predictions are not bad and we have progress toward identifying problems that stand in the way of improving the model. 
Experiment Instructions

Instruction Sheet

You are going to participate in an economics experiment. The instructions are simple and if you follow them carefully you can earn considerable amounts of money. You will be paid in cash unless instructed otherwise.

Eight items are offered for sale through an electronic auction price. You will be allowed to purchase one and only one item. Your earnings will be the difference between what you pay for the item and the value of the item to you. Two different types of items will be auctioned. Four of item A will be auctioned and four units of item B will also be auctioned. All of the items A are identical to you and all of the items B are identical to you. The value to you of any of the A items is shown on your record sheet and the value of any of the B items are also shown on the sheet. However, the values you see may not be the same as the values of other bidders.

After the auction is over you should record the price you paid. The difference between the value of the item shown on your sheet and the price you paid is the amount you earn. This, amount, together with any amount promised as a showup fee, is the amount you take home. Obviously you do not want to pay more for the item than its value to you.

These items will be sold at auction. As you can see there are more people in the room than there are items. Some people will not buy a unit. Should you choose not to buy you can take the OUTSIDE OPTION. It costs you nothing. If you purchase an item you do not get the OUTSIDE OPTION.

The auction is a progressive auction with all items for sale at once. The auction will open with a clock, shown at the top of the screen. It is counting down. When a new bid is submitted the clock will reset. If the clock ever attains zero the auction is over and each item is sold to the current high bidder. None of the items are sold until the clock attains zero. Notice that it is not in your interest to let the clock run down. There is no advantage to waiting until the last second to bid because the clock will simply restart with the full time in response to your bid. By waiting you risk missing the opportunity to bid due to the clock accidentally running out and you have given others time to consider their bids without being rushed.

As the prices of all items increase, they might be out of range for you to profitably buy a unit. At any time during the auction you can take the OUTSIDE OPTION and leave.

Details on the interface and submitting bids will be explained now.

\section{Verbal Instruction Script}


Now that you have read the basic instructions for the experiment, I will lead you through an explanation of the computer interface. Before the actual experiment, I am going to ask you to practice for a few minutes on a sample environment. Please open up your web browser and go to http://eeps58.caltech.edu/hmpractice. Scroll to the bottom of the screen and select "Practice Participant Login" and then "Practice Bidding". This will get you into the bid submission screen. The screen for the experiment will look and function much like this one.

1. The first thing to notice is the box labeled "Time Remaining". This is the countdown clock that determines when the auction ends. This clock will start counting down from 3 minutes and every time anyone submits a bid, it will reset. If the clock ever reaches zero, then the auction is over. There is one clock for all items, so all items are open for bidding until the auction closes. Note that as the auction progresses, we may decrease the starting point of the clock down to 2 minutes or perhaps 1.5. As the clock approaches 0 , you will be notified by flashing lights. If you see these and are willing to bid, you should do so quickly.

2. To the right of this you will see links to "Bidding Rules". The rules under this link are not the rules to be used for this experiment. There is also a screen for "Bidding Screens and Functions." This screen will explain the various boxes on the screen and you can consult it as you are practicing. For now, I will give an overview of the rest of the screen. If you have clicked on either of these links, please click back on the "Highest Offers" link as this takes you back to the main page.

3. You should notice two tables on the screen. I will first direct you to the "Highest Offers" table. This table is where you can see the current prices and minimum required bids for each item. Every item in the auction will be listed by Lot \# and the table will include the bidder ID\# of the current high bidder as well as their bid and what will be required to surpass that bid. In the experiment, to place a bid on an item you will need to surpass the current high bid by at least $5 \%$. That is not listed on this screen but it will be on the experiment screen.

4. You can determine what you wish to bid on by comparing the prices listed in this table with the values listed on your sheet. Look at it now. You will see that there will be two types of items in the experiment, type A and B. There will be 4 items of each type. Items 1-4 will be of type A and 5-8 type B. The amount on your sheet indicates what items of either type are worth to you in the event that you win one. Note that your values may differ from those of other bidders. As you read previously, you will only be able to win a single item and you will be paid the difference between your value and the price you pay in the auction.

5. Those bidders who are unable to win an item will be paid the amount listed as their outside option. Note that the values listed on this sheet will convert to US $\$$ at the 
rate of 100 experimental points or francs to the dollar. Thus if your value is listed as 1000 francs and you pay a price of 400 , your payoff will be 600 francs or $\$ 6$.

6. Now that you understand how to find the prices of items and what the items are worth to you, we can talk about submitting a bid. On the left side of the screen you will see an "Offer Submission Form". This is what you will use to submit your bids. After you have decided which item to bid on and how much you wish to bid, click on the circle next to the item you want to bid on. Then enter the amount of the bid in the offer price box. No commas or $\$$ are needed. Please be careful when entering in your bid amount. An extra zero or two can cost you a large amount of money.

7. After you have entered in your bid amount, selected the correct item and verified both, click on the "Submit Offer" button to submit the bid. You should notice two things happen. First, the time remaining clock resets. Second, if you have become the high bidder on the item, it will be highlighted in yellow. So long as you retain the high bid, it will continue to be highlighted in yellow and you will not need to bid. If someone surpasses your bid, then the license will no longer be highlighted and you may want to place a new bid.

8. Please practice placing bids for a few minutes to make sure you are comfortable with the process. Raise your hand if you have a question or a problem and I will come and help you.

Real link is at http://eeps58.caltech.edu/mark

\section{Quiz}

Identification Number Name

Please answer the following questions after you have been through all of the instructions. The purpose of this quiz is simply to verify that you understand the rules of the experiment.

1. If you were to win item number 3 at a price of 2200 , what would your payoff be in dollars?

2.If you were to win item number 7 at a price of 4200, what would be your payoff in dollars?

3. What would your payoff be if you win nothing in the auction?

4.What does it mean when a cell in the "Highest Offers" table is highlighted in yellow? 